\title{
WAVE BOUNDARY LAYER HYDRODYNAMICS DURING ONSHORE BAR MIGRATION
}

\author{
Martijn Henriquez ${ }^{1}$, Ad Reniers ${ }^{2}$, Gerben Ruessink $^{3}$ and Marcel Stive ${ }^{4}$
}

To study onshore bar migration and the accompanying intra-wave sediment transport a wave flume experiment was conducted. The wave flume had a rigid bottom with a single bar profile. The focus of the experiment was to measure the hydrodynamics in the wave bottom boundary layer. The results show that the skewness of bottom stress is not only related to wave skewness but also to wave asymmetry.

Keywords: non-linear waves; wave bottom boundary layer, bottom shear stress; nearshore morphology

\section{INTRODUCTION}

The orbital flow under non-linear waves in the nearshore can transport sediment and therefore change the underlying topography. A good example of this is the onshore migration of nearshore bars (Aubrey 1979, Wright and Short 1984). Modeling efforts of onshore bar migration have commonly failed, indicating that the accompanying transport processes are poorly understood (Nielsen 2006, Henderson et al. 2004, Hoefel and Elgar 2003, Madsen 1974).

Presently a few hypotheses can be distinguished in literatures that explain the processes responsible for onshore bar migration. Before getting to these processes it is practical to define skewness and asymmetry. The skewness $S k$ of variable $X$ is defined as $\left\langle(X-\mu)^{3}\right\rangle / \sigma^{3}$ where \langle\rangle is the mean operator, $\mu$ is the mean and $\sigma$ is the standard deviation of variable $X$ (Groeneveld and Meeden 1984). The asymmetry As of variable $X$ is defined as $-\left\langle(H(X-\mu))^{3}\right\rangle / \sigma^{3}$ where $H$ is the Hilbert transform (Kennedy et al. 2000, Henderson et al. 2004). Below, a non-exhaustive list of the most common processes which contribute to onshore bar migration:

1. skewed bottom stresses due to skewed free-stream orbital flow velocities (Bowen 1980, Bailard 1981);

2. skewed bottom stresses due to conversion of free-stream flow asymmetry to flow skewness in the wave bottom boundary layer (Henderson et al. 2004);

3. skewed bottom stresses due to difference in wave bottom boundary layer development in on-and offshore flow direction (Nielsen 2006);

4. large horizontal pressure gradients under the steep wave front (Hoefel and Elgar 2003);

5. onshore directed mean flow in the wave bottom boundary layer (Longuet-Higgins 1953, Trowbridge and Young 1989).

To study processes 1,2,3 and 5 a wave flume experiment was conducted at the WaterLab of Delft University of Technology in the Netherlands.

\section{EXPERIMENT}

The flume has a length of $40 \mathrm{~m}$, a width of $0.8 \mathrm{~m}$ and a water depth of $0.5 \mathrm{~m}$. In the flume a rigid single bar profile was build (see Fig. 1). The bottom profile and wave conditions were derived from tests with a mobile bed where the bar moved onshore (Henriquez et al. 2008). The top of the bar is approximately $0.15 \mathrm{~m}$ below the mean water level. Granular sediment with a grain size of $0.54 \mathrm{~mm}$ was glued to the surface to provide bottom roughness (for scale assumptions see Henriquez et al. 2008).

The waves are regular with a height of $0.1 \mathrm{~m}$ and a period of $1.8 \mathrm{~s}$. The vertical and horizontal flow velocities within the wave bottom boundary layer were measured with Particle Image Velocimetry (PIV) at 6 locations over the bar (see Fig. 1). The laser sheet for PIV was inserted into the water from the water surface using a streamlined window. The camera was placed outside of the flume (flume wall is transparent). The camera had a field of view of approximately $10 \times 10 \mathrm{~mm}^{2}$ (see Fig. 2). The camera images were processed resulting in a velocity vector for every $0.37 \times 0.37 \mathrm{~mm}^{2}$.

\footnotetext{
${ }^{1}$ Hydraulic Engineering, Delft Universtity of Technology, Stevinweg 1, Delft, 2600 GA, Netherlands

${ }^{2}$ Applied Marine Physics, RSMAS, 4600 Rickenbacker Causeway, Miami, FL33149, USA

${ }_{3}^{3}$ Physical Geography, Utrecht University, Heidelberglaan 2, Utrecht, 3584 CS, Netherlands

${ }^{4}$ Hydraulic Engineering, Delft Universtity of Technology, Stevinweg 1, Delft, 2600 GA, Netherlands
} 


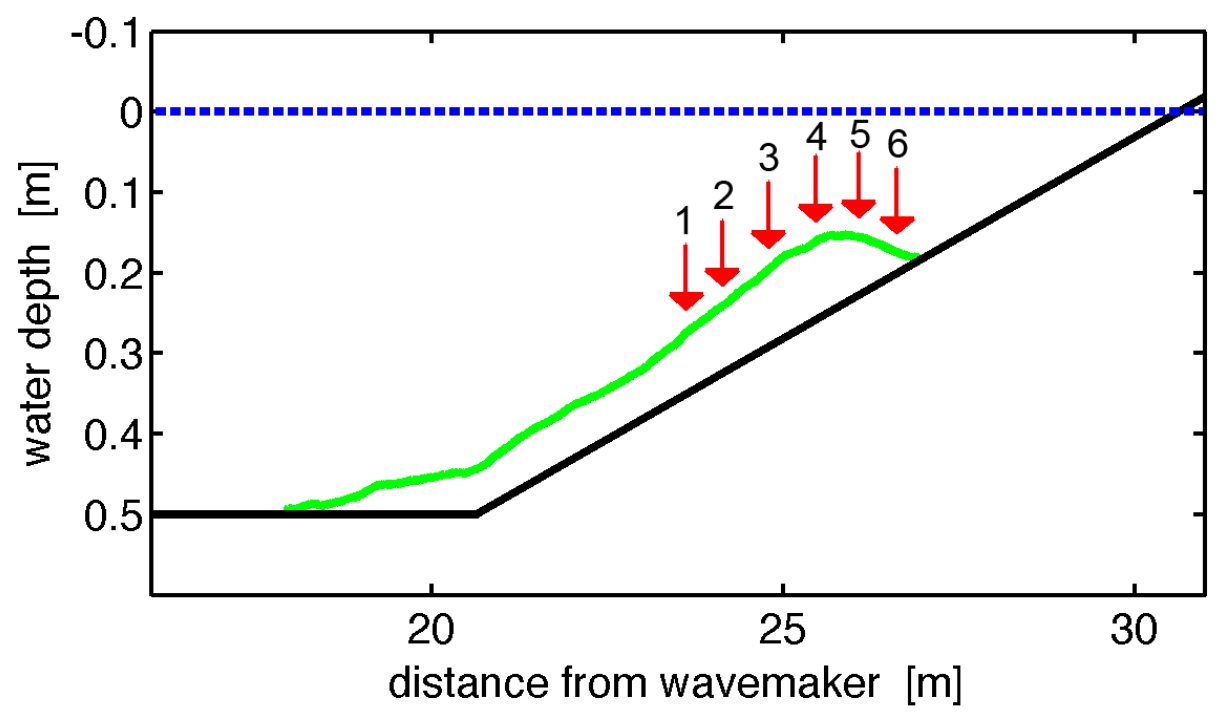

Figure 1. Bottom profile. The barred profile is build on top of a plane 1:20 slope. Dotted line is the mean water level. Arrows denote measurement locations.

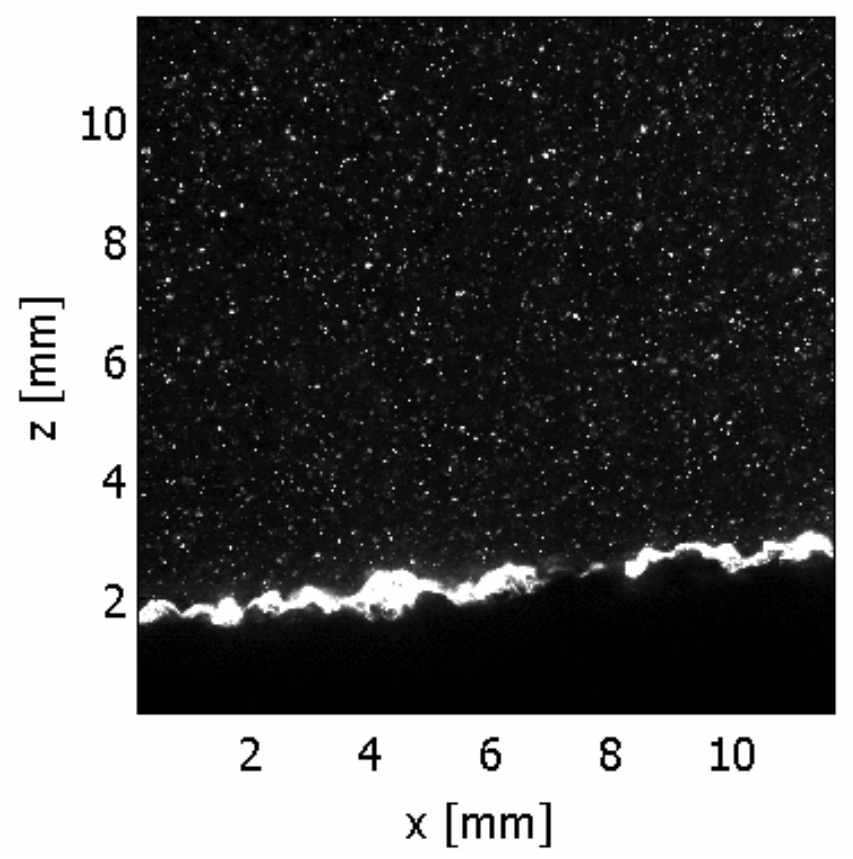

Figure 2. Camera image snapshot. The dots are seeding illuminated by the laser sheet. Dark area without seeds is the bed. 
The flow velocity vector is decomposed into tangential and normal components. The tangential component $u$ is tangent to the bottom and positive in the wave direction. The normal component $w$ is normal to the bottom and positive upward.

The use of regular waves enables ensemble averaging which results in:

- the mean flow velocity $\langle u\rangle$ and $\langle w\rangle$;

- the orbital flow velocities $\tilde{u}$ and $\tilde{w}$;

- turbulent fluctuations $u^{\prime}$ and $w^{\prime}$

over one wave cycle. An ensemble consists of 120 waves. Measurements were conducted at a rate of 15 $\mathrm{Hz}$ resulting in 27 time steps (phases) in one wave cycle.

\section{RESULTS}

\section{Free-Stream Flow Velocity}

Fig. 3 (upper panel) shows the horizontal free-stream flow velocity for the locations 1 to 4 . This is the flow velocity at $8 \mathrm{~mm}$ above the bed which is outside the wave bottom boundary layer. The wave clearly transforms as it shoals on the bar:

- $\quad$ the maximum onshore flow velocity increases which adds skewness $S k_{u}$;

- the flow velocity signal becomes pitched forward which adds asymmetry $A s_{u}$;

- the maximum offshore flow velocity stays approximately the same.

\section{Bottom Stresses}

Fig. 3 (lower panel) shows the bottom stresses for location 1 to 4 . The bottom stresses $\tau$ are derived from the turbulent fluctuations $u^{\prime}$ and $w^{\prime}$ at $0.5 \mathrm{~mm}$ above the bed using the relation $\tau=-\rho \overline{u^{\prime} w^{\prime}}$. The following remarks can be made:

- onshore-directed bottom stresses increase dramatically from location 1 to 4 while offshore-directed bottom stresses stay relatively small;

- $\quad$ there is a phase lag between the turbulent stresses and the free-stream horizontal flow velocity;

- as the wave shoals on the bar the magnitude of the bottom stresses increase much more than the magnitude of the free-stream flow velocity.

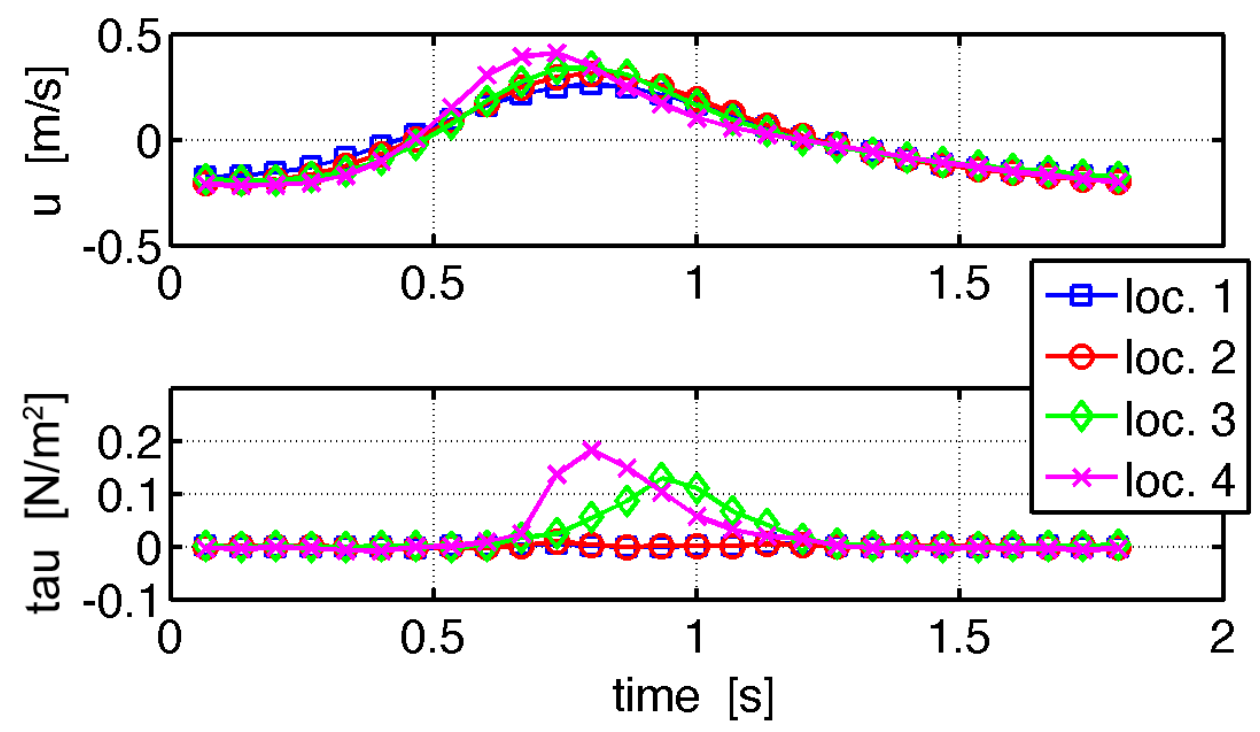

Figure 3. Upper panel: free-stream horizontal flow velocity at $8 \mathrm{~mm}$ above the bed for location 1 to 4 . Lower panel: bottom stresses for location 1 to 4 . 


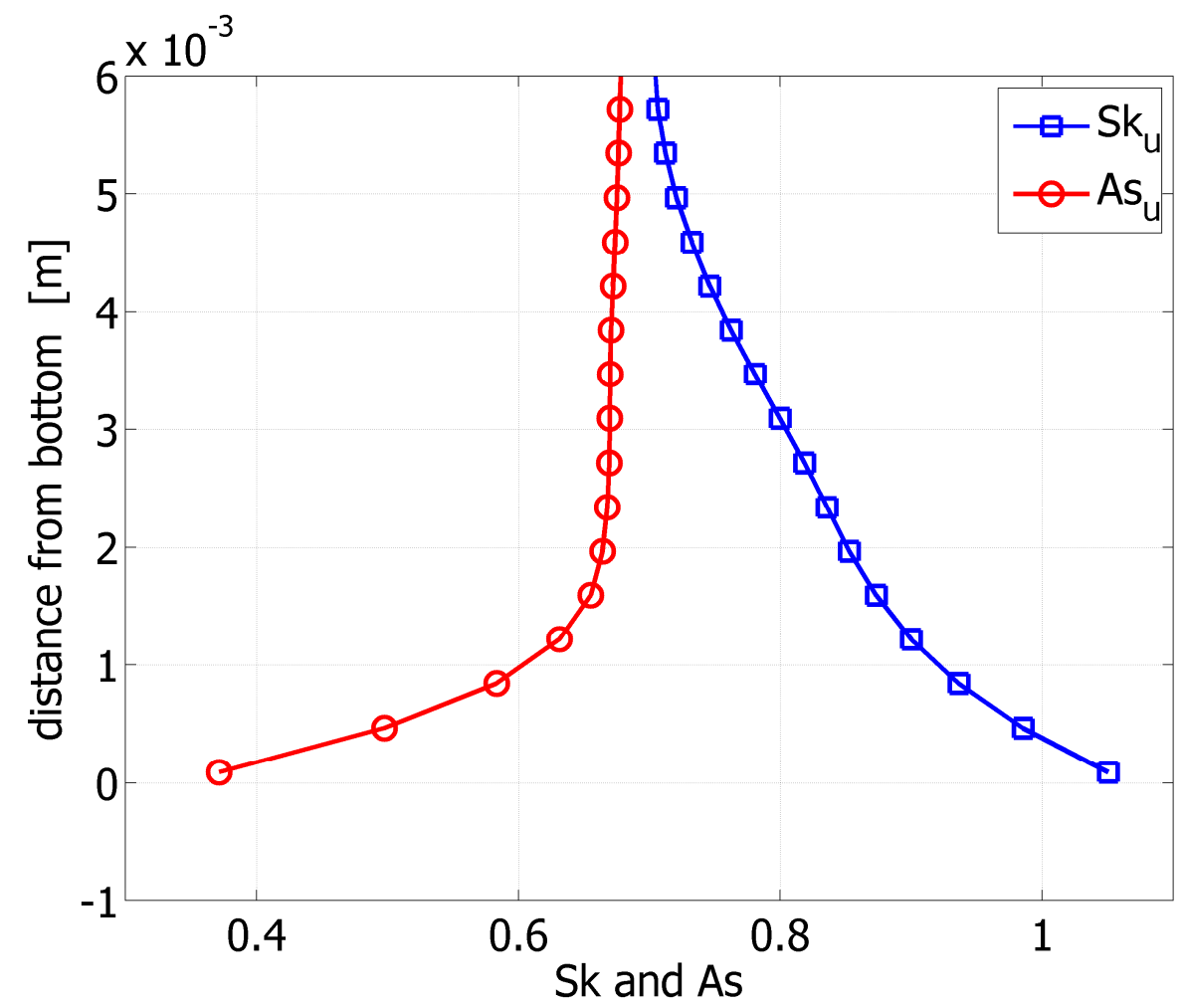

Figure 4. Skewness and asymmetry of the horizontal flow velocity at location 4.

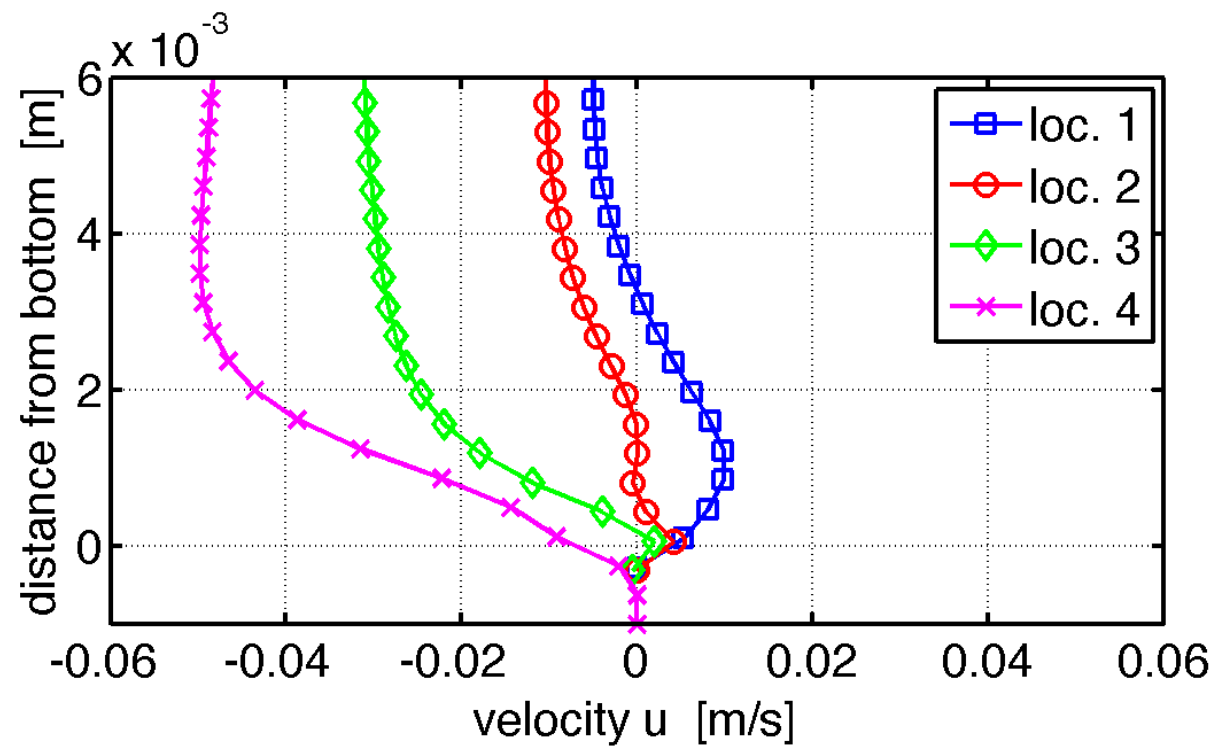

Figure 5. Mean horizontal flow velocity for location 1 to 4. 


\section{Skewness and Asymmetry}

Fig. 4 shows the vertical profile of the horizontal flow velocity skewness $S k_{u}$ and asymmetry $A s_{u}$ at location 4. At this location the skewness $S k_{u}$ increases and the asymmetry $A s_{u}$ decreases towards the bottom.

\section{Mean Flow Velocity}

Fig. 5 shows the vertical profiles of the horizontal mean flow velocity at location 1 to 4 . At the most offshore location (location 1) there is an onshore-directed flow which could be boundary layer streaming (Longuet-Higgins 1953). Above the wave boundary layer the flow is directed offshore, most likely to compensate for the positive mass flux by the waves also known as Stokes drift (Stokes 1847, Longuet-Higgins 1953). As the water depth becomes less from location 1 to 4 the return flow becomes much larger and dominates the onshore-directed streaming.

\section{CONCLUSIONS}

Turbulent stresses during the onshore phase of the orbital flow velocity increase by a factor of 2 from location 3 to 4 . This increase cannot solely be explained by the increase of the free-stream velocity. Therefore, part of the increase is related to the increase in wave asymmetry.

The skewness of the horizontal flow velocity increases in the wave bottom boundary layer. On the contrary, the asymmetry of the horizontal flow velocity decreases in the wave bottom boundary layer. This is in line with Henderson et al. (2004).

The offshore-directed return flow dominates the onshore-directed wave boundary layer streaming as the water depth becomes less. Therefore, in the wave flume, it is unlikely that streaming contributes to the onshore bar migration under these conditions.

\section{ACKNOWLEDGMENTS}

This project is funded by the Technology Foundation STW, applied science division of NWO, in The Netherlands, under project number DCB.07908.

\section{REFERENCES}

Aubrey, D. 1979. Seasonal patterns of onshore/offshore sediment movement, Journal of Geophysical Research, 84, 6347-6354.

Bailard, J.A. 1981. An energetics total load sediment transport model for a plane sloping beach. Journal of Geophysical Research 86, 10938-10954.

Bowen, A.J. 1980. Simple models of nearshore sedimentation: beach profiles and longshore bars, The Coastline of Canada, 80-10, 1-11.

Groeneveld, R.A., and G. Meeden. 1984. Measuring Skewness and Kurtosis, The Statistician, 33 (4), 391-399.

Henderson, S.M., J.S. Allen, and P.A. Newberger. 2004. Nearshore sandbar migration predicted by an eddy-diffusive boundary layer model, Journal of Geophysical Research, 109.

Henriquez, M., M.J.F. Stive, A.J.H.M. Reniers, B.G. Ruessink, T.P. Stanton and D.L. Foster. 2008. On the scaling of sediment transport in the nearshore, Coastlab 2008 Conference, IAHR, 193-204.

Hoefel, F., and S. Elgar. 2003. Wave-induced sediment transport and sandbar migration, Science.

Kennedy, A.B., Q. Chen, J.T. Kirby, and R.A. Dalrymple. 2000, Boussinesq modeling of wave transformation, breaking and runup. I: One dimension, J. Waterway, Port, Coastal and Ocean Engrng., 126, 39-47.

Longuet-Higgins, M.S. 1953. Mass transport in water waves, Phil. Trans. R. Soc. (A) 245, 535-581.

Madsen, O.S. 1974. Stability of a sand bed under breaking waves, Proceedings of 14th International Conf. on Coastal Engineering, 776-794.

Nielsen, P. 2006. Sheet flow sediment transport under waves with acceleration skewness and boundary layer streaming, Coastal Engineering, 53, 749-758.

Stokes, G.G. 1847. On the theory of oscillatory waves, Trans. Camb. Phil. Soc. 8, 441-445.

Trowbridge, J.H., and D. Young. 1989. Sand transport by unbroken water waves under sheet flow conditions, Journal of Geophysical Research, 94, 10971-10991.

Wright, L.D., and A.D. Short. 1984. Morphodynamics variability of surf zones and beaches: a synthesis, Marine Geology, 26, 93-118. 